\title{
Editorial
}

\section{Sustainable Buildings in Sustainable Cities: A Reciprocal Relation}

\author{
Alexander Koutamanis
}

Citation: Koutamanis, A. Sustainable Buildings in Sustainable Cities: A Reciprocal Relation.

Sustainability 2021, 13, 3077.

https:/ / doi.org/10.3390/su13063077

Received: 9 March 2021

Accepted: 10 March 2021

Published: 11 March 2021

Publisher's Note: MDPI stays neutral with regard to jurisdictional claims in published maps and institutional affiliations.

Copyright: (C) 2021 by the author. Licensee MDPI, Basel, Switzerland. This article is an open access article distributed under the terms and conditions of the Creative Commons Attribution (CC BY) license (https:// creativecommons.org/licenses/by/ $4.0 /)$.
Faculty of Architecture, Delft University of Technology, 2628 CD Delft, The Netherlands; a.koutamanis@tudelft.nl

\section{Many Views, One Phenomenon}

It appears that each discipline views cities differently, through different perspectives, abstractions and metaphors. Some see a city as a municipal organisation-a social view. Others approach cities as a collection of buildings and other physical structures, usually because they are in the business of designing and planning the built environment. Yet others adopt a systemic view and treat cities as ecosystems or, more recently and arguably more interestingly, as assemblages: open-ended gatherings at a place and at a variety of scales, enabling coexistence without assuming interaction [1,2].

Most of these views seem legitimate and reasonable. They are founded in extensive reasoning, substantial scholarship and thorough analyses of specific aspects of the physical, social or cultural environment. Most are also entrenched in different disciplines or schools of thought. Consequently, we are often asked to choose and adopt a view in order to fit into a certain environment, either in agreement or in opposition.

Such conformity (either positively or negatively expressed), however, restricts our view to specific aspects or levels of abstraction and increases the gulf between different disciplines. The end result is failure to communicate and work together at a larger scale, which is arguably what we need in order to understand current and emerging problems, and to progress towards the goals we set for our cities.

Rather than sticking to a specific view, we should be doing two things. The first is to accept that most views have at least some validity and value, and that linking them to each other could help us to describe and explain better what actually happens in our highly dynamic and complex time. There is a lot that we can learn from others.

Secondly, we need to question the underlying assumptions that may render views inflexible, incompatible, axiomatic, biased or limiting. Hidden behind layers of reasoning and refinement, such assumptions often escape scrutiny and become accepted as universal truths or, minimally, as self-evident goals to which whole industries or societies should subscribe. Metaphors are among the prime examples of this. For example, describing social organisations as plants and suggesting that they go through successive periods of growth, maturity and decline may appeal to our imagination but ultimately reduces all facts to a single story instead of helping to explain how they indicate different, intertwined stories with various outcomes [3].

\section{Shared Goals and Interdependencies}

In this issue, we focus on how sustainability, an acknowledged goal for cities and buildings, translates not only to either level but also to the relations between them. Building construction is often blamed for resource overconsumption but comparisons between embodied energy in the built environment and annual operational energy for the use of the same built environment suggest that the latter may be three or four times higher than the former, with transport accounting for almost half of all operational energy [4].

This does not exonerate building construction from accusations of inefficiency and waste, which are well documented [5], but illustrates that their contributions to the city can be both direct and indirect, as well as periodic or continuous. Building construction, 
maintenance and renovation are costly periodic events but the operation of buildings results in continuous costs, which arguably depend more on the activities that take place in buildings. The buildings themselves merely accommodate these activities and constrain their costs. Inefficiencies should not be blamed on the specific buildings but investigated as probable mismatches between activities and the buildings.

Transport, on the other hand, is indirectly related to buildings: we move between places allocated to various activities and most of these places are in or around buildings. This, too, can be blamed on buildings but more specifically on urban planning decisions regarding building location, density, etc. This is a more abstract level of the built environment; moreover, it is one determined less by the buildings themselves and more by general principles and social structures of development and governance.

Such interdependencies between buildings and cities reveal that the achievement of goals such as sustainability is subject to understanding how the one shapes and is shaped by the other as unambiguously and transparently as possible. Particular points of attention are the ways in which these interdependencies are translated into pragmatic measures that agree with established practices, e.g., how existing construction processes can be made more sustainable or how existing building types can form sustainable neighbourhoods, as pragmatism often involves unproductive conformity to outdated ways of thinking and doing.

\section{The Whole and the Parts}

It seems therefore logical to suggest that a city should be considered as more than a collection of buildings. This brings forward the physical parts of the city that remain hidden or vague in the background of buildings, such as the infrastructure that connects buildings and the utilities that ensure their functioning. The significance of these aspects for the performance of both cities and buildings, for operational energy consumption and, above all, for constraining change in the city and individual buildings cannot be underestimated.

Equally important are relations between building and other things in the city, both physical and conceptual. Among the latter are levels of abstraction that determine what we consider to be parts of the city, from a street and an urban block to informal neighbourhoods and administrative subdivisions. These are not just terms; they also determine our perception of the city, including how data are collected and summarised, often with distorting effects. Physical relations, on the other hand, are often ignored because they tend to require zooming in on the details of individual buildings and their context. Such levels may be deemed too costly and are therefore avoided.

The problem is that performance is often determined by local, physical relations. The visitor of any urban place in the Netherlands cannot help but notice the solar panels that adorn many roofs but also that quite a few of these are too small in surface or positioned towards unfavourable orientations (or favourable ones but shaded by trees or other buildings), simply because the roofs on which they are place do not afford anything else. The basic principles for effective and efficient deployment of solar panels are widely known and immediately available on the Internet, yet they seem not to be respected by homeowners and municipal authorities that presumably have subsidised the panels through sustainability policies. One wonders how effective these policies and investments are.

\section{Top Down and Bottom Up, Proxies and Measurements}

Understanding and controlling the reciprocal relation between buildings and cities is key to pursuing any goal. This involves both the bottom-up contributions of buildings and the top-down constraints of cities. In the bottom-up direction, we need to understand better how the behaviour and performance of individual buildings affects a city. To use an example not directly linked to sustainability, it is rather alarming that in most codes and regulations, fire safety is treated as if it were a problem for each building separately, as if fire in one building does not affect adjacent buildings and areas almost immediately. Getting occupants out of a specific building does not necessarily mean that they are safe or 
that their flow does not conflict with other flows, either from other buildings or from the emergency services attending the fire.

One of the key problems in the bottom-up direction is that we only too frequently resort to proxies. In energy studies, for example, there is an inexplicable popular insistence on floor areas as an indication of energy requirements or consumption, even though every textbook on building energy performance warns that this is meaningless because, while some internal loads, such as occupancy, lighting and equipment, are linearly linked with floor area, heat gain or loss occurring through the envelope, the surface of which has a non-linear relation with the floor area. It also follows that measuring energy consumption per floor area unit is not realistic because larger buildings require less energy per area unit [6].

It seems that the choice of proxies is less motivated by meaning and more by availability: rather than allocating admittedly considerable effort to collecting the right data, many researchers simply utilise what is readily available. This is why, e.g., the year of construction is often used as a proxy for building quality and material content: information about when a building was realised is often available in the public domain, as are the construction technologies of that time, while collecting information such as the nature and timing of subsequent renovations may involve extensive research involving public and private sources. That such proxies lead to the wrong conclusions is apparently not sufficiently motivating for the development of better techniques for collecting relevant and reliable data [7].

In the top-down direction, we need to be more explicit and detailed about how a city constrains the form and performance of a building. There are many physical and conceptual structures underlying the relation between cities and buildings, including building codes and planning regulations, which are not always as logical and effective as one might assume. It is saddening, for example, that in most European cities, building facades on both sides of a street are subject to the same requirements and rules, even though one may be exposed to inclement north winds, while the other suffers from solar overheating from the south. It appears that having the same morphologies on both sides of the street matters more than energy consumption or comfort.

One should also consider the scale and scope of sustainability measures and improvements with respect to the existing situation and its continuity, as many cities and towns comprise already older buildings that may remain in existence for the foreseeable future, forming the largest share of future building stock. High book value and durability, coupled with a preservation mentality, conspire to prolong in-use life, reduce change and limit performance in buildings [8]. Even when renovation and new developments manage to attain higher performance in individual buildings, other factors, such as rising living standards and increasing house sizes or numbers, may keep city performance at the same high plateau as before [9].

These factors reveal that societies and cities have more goals, which inevitably interfere with sustainability. In recent years, many Dutch urban areas, and especially the Randstad (the conurbation along the west coast), experience high demand for housing of all kinds, from affordable dwellings for first-time homeowners to comfortable houses for larger families and adapted units for the elderly. This puts significant stress on the resources of most municipalities. Finding a place to build new housing, having adequate public facilities for the growing number of citizens and avoiding increasing the already considerable traffic problems are all becoming increasingly hard. Building fast and cheaply seems the popular answer. At the same time, there is a national programme of energy transition, which requires considerable investment to improve existing buildings and ensure that new buildings meet the requirements of the future. It is still uncertain how the two goals will be reconciled and how they will affect cities. 


\section{Some Questions (Rather than Conclusions)}

The main aim of this issue is not to propose easy solutions based on questionable hypotheses and restrictive principles but, as discussed above, to analyse the existing situation and probable development of cities towards a better understanding of how buildings and cities relate to each other. Through this, we expect to be able to identify possibilities and limitations that must be either adapted or respected and prioritised in order to take positive steps in the direction of a sustainable future. We therefore invite you to respond to the questions raised in this brief account of our intentions with this issue and contribute to the study of the reciprocal relation between sustainable buildings and sustainable cities, specifying fruitful directions for further research.

Conflicts of Interest: The author declare no conflict of interest.

\section{References}

1. Ong, A.; Collier, S.J. Global Assemblages: Technology, Politics, and Ethics as Anthropological Problems; Blackwell Publishing: Malden, MA, USA, 2005.

2. Tsing, A.L. The Mushroom at the End of the World: On the Possibility of Life in Capitalist Ruins; Princeton University Press: Princeton, NJ, USA, 2015.

3. Greene, M. A Shared World: Christians and Muslims in the Early Modern Mediterranean; Princeton University Press: Princeton, NJ, USA, 2000.

4. Troy, P.; Holloway, D.; Pullen, S.; Bunker, R. Embodied and Operational Energy Consumption in the City. Urban Policy Res. 2003, 21,9-44. [CrossRef]

5. Pacheco-Torgal, F.; Ding, Y.; Colangelo, F.; Tuladhar, R.; Koutamanis, A. (Eds.) Advances in Construction and Demolition Waste Recycling; Woodhead Publishing: Duxford, UK, 2020.

6. Garg, V.; Mathur, J.; Tatali, S.; Bhatia, A. Building Energy Simulation: A Workbook Using Design Builder; CRC Press: Boca Raton FL, USA, 2017.

7. Koutamanis, A.; van Reijn, B.; van Bueren, E. Urban mining and buildings: A review of possibilities and limitations. Resour. Conserv. Recycl. 2018, 138, 32-39. [CrossRef]

8. Koutamanis, A. Building information modeling for construction and demolition waste minimization. In Advances in Construction and Demolition Waste Recycling; Pacheco-Torgal, F., Ding, Y., Colangelo, F., Tuladhar, R., Koutamanis, A., Eds.; Woodhead Publishing: Duxford, UK, 2020; pp. 101-120.

9. Trentmann, F. Empire of Things: How We Became a World of Consumers, from the Fifteenth Century to the Twenty-First; Allen Lane: London, UK, 2016. 